\title{
Sobre palavras que vendem coisas: o glossário do risco em anúncios de revistas
}

\author{
Mary Jane P. Spink \\ Dolores Galindo \\ Raquel Noel Ribeiro \\ Maria Annita Ornellas \\ Pontifícia Universidade Católica de São Paulo
}

\begin{abstract}
Resumo
Este artigo visa entender como a linguagem dos riscos, nas suas diferentes tradições (risco-perigo, riscoprobabilidade e risco-aventura), é utilizada para vender produtos em anúncios veiculados em revistas vendidas em bancas. Com esse objetivo, tomamos os anúncios como gêneros de discurso que fazem circular materialidades (artefatos cotidianos) passíveis de comercialização (na forma de bens simbólicos) e que são necessariamente endereçados a públicos específicos. Foi definida uma amostra de 101 revistas com base nas categorias utilizadas pelo Anuário de Mídia - Revistas. A análise levou em consideração as palavras empregadas nos anúncios, a categoria de produtos e a temática da revista. Conclui-se que, embora os riscos vendam produtos, trata-se mais do controle de riscos potenciais do que de apologia do risco. Mesmo quando os produtos são associados ao risco-aventura, vendem-se, de fato, emoções associadas à experiência do risco que são sustentadas por uma diversidade de estratégias de segurança.
\end{abstract}

Palavras-chave: práticas discursivas; linguagem dos riscos; mídia; anúncios

\begin{abstract}
On words that sell things: risk glossaries in media advertisements. The aim of this research was to understand how the discursive traditions (risk as danger; risk as probability and risk as adventure) of the language of risk are used in magazine advertisements. Advertisements were defined as genres of discourse that put into circulation materiality (quotidian artifacts) that can be commercialized (as symbolic goods) and are necessarily addressed to a specific public. A sample of 101 magazines was defined using the categories of the Anuário de Mídia - Revistas. The analysis took into account the words used in the advertisements, the category of goods been advertised and the type of magazine in which they appeared. Although risk does sell products, the focus tends to be on risk control rather than on an apology of risk. Even when products are associated to risk as adventure, what is being sold is the sensation of risk counterbalanced by a diversity of safety strategies.
\end{abstract}

Key words: discursive practices; language of risk; media; advertisements

$\mathrm{E}$ ste artigo visa entender como a linguagem dos riscos, nas suas diferentes tradições, é utilizada para vender produtos em anúncios divulgados em revistas vendidas em bancas. Por meio do estudo dos glossários de risco, nas suas três tradições discursivas (risco-perigo, risco-probabilidade e risco-aventura) buscamos responder a três perguntas. Quais tradições discursivas de risco são atualizadas na venda de produtos (artefatos técnicos)? Quais produtos são vendidos? E, por fim: para quem são vendidos os produtos cujos anúncios fazem uso do glossário de risco?

$\mathrm{O}$ estudo aqui relatado insere-se no conjunto de reflexões contemporâneas sobre as novas modalidades de riscos que se fazem presentes na modernidade tardia, ou sociedade de risco - expressão cunhada por Beck (1993) e Giddens (1991, 1998). A modernidade caracteriza-se pela ruptura com a tradição. E, assim como a sociedade industrial dissolveu a estrutura feudal, a sociedade de risco começa a diluir as estruturas da sociedade industrial, incluindo aí a compreensão clássica de ciência e tecnologia, assim como os modos de ser no trabalho, no lazer, na família e na sexualidade.

Para esses autores, são três as principais características da sociedade de risco. Primeiramente, a globalização, que leva 
à desterritorialização - "o entrelaçamento de eventos sociais e relações sociais que estão distantes de contextos locais" (Giddens, 1991, p. 21). Em segundo lugar, o acirramento da individualização decorrente da destradicionalização - processo que substitui biografias pautadas pela inserção em classe por biografias reflexivas que dependem das decisões de cada ator. E, como terceira característica, a reflexividade, ou seja, "a suscetibilidade da maior parte dos aspectos da atividade social à revisão continuada à luz de novas informações ou conhecimentos" (Giddens, 1991, p. 20).

A modernidade tardia é, por definição, uma sociedade de risco. A problemática central na modernidade clássica era a distribuição da riqueza ao passo que, na modernidade tardia, a questão central passou a ser a distribuição dos riscos. Assim, se a igualdade era a palavra-chave da modernidade clássica, a força motivadora da sociedade de risco passou a ser a segurança, com a conseqüente necessidade de desenvolvimento de "formas sistemáticas de lidar com os perigos e as inseguranças engendradas e introduzidas pelo próprio processo de modernização" (Beck,1993, p. 21). Decorre disso a onipresença de discursos voltados a definir, prevenir ou controlar esses riscos manufaturados (Giddens, 1998).

Investigações anteriores sobre os discursos sobre risco que circulam na sociedade haviam indicado um aumento do uso da linguagem dos riscos na mídia (Spink, Medrado, \& Mello, 2002), assim como no consumo de atividades e produtos de risco-aventura (Spink, Aragaki, \& Alves, 2005; Spink, Galindo, Cañas, \& Souza, 2004). Permitiram entrever que nos deparamos atualmente com novas modalidades de uso de repertórios interpretativos sobre risco, sendo uma dessas modalidades justamente o glossário do risco para venda de artefatos técnicos cotidianos por meio de anúncios publicitários.

Para fins deste artigo, definimos anúncios como gêneros de discurso que fazem circular produtos (artefatos cotidianos) passíveis de comercialização (na forma de bens simbólicos) e que são necessariamente endereçados a públicos específicos. Os objetos ou serviços anunciados têm seus usos específicos (finalidades técnicas), mas podem ser modificados em função de processos de construção de sentido que incluem o uso da linguagem dos riscos em suas diferentes tradições.

\section{Anúncios como linguagens sociais}

Os anúncios, segundo Cortese (1999), precisam ser considerados não apenas em sua função manifesta de persuadir consumidores a comprar uma marca específica de produto ou serviço, mas também como artefatos culturais.

Os anúncios constituem um dos mais poderosos mecanismos por meio dos quais os membros de uma sociedade assimilam sua herança cultural e as ideologias culturais de dominação. Ideologias referem-se a imagens, conceitos e premissas que compõem os enquadres por meio dos quais representamos, interpretamos, compreendemos e buscamos compreender algum ponto de vista da vida social. (Cortese, 1999, p. 2)

Como artefatos culturais, os anúncios co-optam aquilo que é corrente na cultura. A publicidade não formula valores e atitudes próprias; absorve e re-direciona repertórios que o público alvo já compartilha. Essa re-interpretação daquilo que já é corrente numa determinada cultura tem duplo efeito: de familiarizar consumidores potenciais com determinados estilos de vida e, concomitantemente, legitimar o produto ou serviço. Diz o autor:

As imagens simbólicas nos anúncios criam um elo entre o produto ou serviço que é oferecido e traços sociais desejáveis e plenos de sentido de modo a persuadir o consumidor que o produto ou serviço produzirá um estilo de vida altamente cobiçado. (Cortese, 1999, p. 11)

A mídia é uma poderosa ferramenta para fazer circular esses repertórios de modo que a análise daquilo que é por ela veiculado possibilita entender como uma determinada cultura cria e legitima determinados estilos de vida. No caso específico das revistas, há uma relação intrínseca, cada vez mais manifesta, entre mídia e anúncios, seja porque os anunciantes bancam parte dos custos de produção das revistas, seja porque mídia e anúncios são endereçados a públicos muito específicos criando uma cadeia de interanimação dialógica (Bakhtin, 1994) entre leitores-consumidores, proposta editorial da mídia específica e anunciantes de produtos.

Scalzo (2004) fala da importância dos anúncios no sucesso de uma revista uma vez que os índices de circulação e a importância do público-alvo no mercado de consumo atraem anunciantes e financiam parte dos custos de produção das revistas. Todavia, adverte que há necessidade de manter uma boa proporção entre anúncios e páginas. Diz ela que, dependendo do tipo de revista, os números ficam entre $20 \%$ e $40 \%$ de anúncios para $80 \%$ a $60 \%$ de material editorial respectivamente (Scalzo, 2004).

Embora reconhecendo a necessidade de conquistar anunciantes para viabilizar o projeto editorial, Scalzo alerta para as tensões possíveis entre a redação (que tem como cliente o leitor) e a área comercial (que tem anunciantes como clientes). Essa relação potencialmente conflituosa, no caso do Brasil, é intermediada pelo Conselho Nacional de Auto-Regulamentação Publicitária, CONAR.

A idéia da criação de um mecanismo que fosse capaz de livrar a publicidade dos controles autoritários do governo data dos anos de 1970, quando havia um controle rígido da mídia por parte do governo militar. Seguindo o exemplo de países como o Canadá e a Inglaterra, buscou-se criar um tipo de controle que ficasse a cargo dos próprios profissionais do ramo, com o apoio de veículos de comunicação e estando comprometido com a defesa dos preceitos básicos da ética publicitária. O primeiro Código Brasileiro de Auto-Regulamentação Publicitária foi aprovado em 1978 pela comunidade publicitária, sendo ainda hoje o documento que orienta a ação do CONAR (Schneider, 2005). Passou, contudo, por várias revisões que levaram à introdução de anexos diversos relacionados à publicidade de produtos que, paulatinamente, passaram a ser objeto de regulação por parte do governo, como as bebidas alcoólicas, produtos de fumo, medicamentos e serviços de saúde.

Em suma, como produtos culturais e como linguagem social os anúncios fazem circular repertórios que integram complexas redes que envolvem públicos e suas inserções sociais, produtores culturais, anunciantes de produtos e serviços, entidades 
legisladoras da sociedade civil e órgãos governamentais. Nessa complexidade, os anúncios permitem refletir sobre certas dicotomias instituídas que cindem, por exemplo, práticas discursivas (imagéticas e textuais) e materialidades.

\section{Sobre a falsa dicotomia entre discursos, imagens e materialidades}

Anúncios vendem produtos e serviços, ou seja, usam linguagem e imagens para seduzir consumidores a comprar seus produtos e serviços: leite, sapatos, pacotes turísticos, carteiras de investimentos, enfim, materialidades. Entretanto, ao nos referirmos às materialidades não estamos propondo a existência de um âmbito extra-discursivo que deva ser anexado ao campo discursivo. Ao contrário, o que se busca com a inclusão das materialidades na análise de produção de sentidos é uma articulação mais complexa que implica ressignificação daquilo que usualmente é entendido como matéria, materialidade ou, ainda, materializações.

Ao trabalhar com linguagem numa perspectiva construcionista, ouvimos advertências do tipo: se tudo é discurso, o que acontece com o corpo, com os objetos? Se tudo é texto, o que dizer da dor, do sofrimento mental e da violência? Resumidamente, ouvimos o lamento: no pós-estruturalismo há alguma matéria que importa? Mas, se, como sugere Butler (2002), invertermos o questionamento, podemos perguntar: como a materialidade chegou a ser um signo de irredutibilidade? Seria a materialidade uma superfície ou um lugar onde, ou a partir do qual, são geradas significações? O que ocupa o lugar de materialidade não construída? E, ainda, que construções ficam excluídas em virtude da representação de um determinado lugar como um exterior que está debaixo (é superfície) da construção?

Ser discursivamente construído e ser material não são categorias excludentes e qualquer resposta ou pergunta nessa direção redundará numa discussão estéril. Pois, "essa materialidade irredutível se constrói através de uma problemática matriz (...), a prática discursiva por meio da qual lhe é atribuída um caráter irredutível simultaneamente ontologiza e fixa (numa dada matriz)" (Butler, 2002, p. 56).

Butler, tomando como problema central a materialidade do corpo, alia-se ao conjunto de autores que enfatizam a importância da noção de matéria. Mas não a concebe na acepção mais comum de um lugar ou uma superfície determinada - por exemplo, que a materialidade do corpo é a carne. Ao invés disso, propõe uma concepção mais fluida de movimentos de materialização que se estabilizam através do tempo e que necessitam do tempo para exercer o papel de uma fronteira, adquirir densidade suficiente para que nele se inscrevam sentidos e relações de poder.

Assim, ao invés de perguntarmos pela matéria entendida como "coisas que a partir de determinado momento passam a estar aí", é mais importante perguntar pelos modos e pelas normas reguladoras que materializam algo, o corpo ou o sapato que compramos. Para Butler (2002), a noção de materialização poderia ser uma interessante alternativa à noção já desgastada de construção. A autora diz:

Eu proporia, no lugar destas concepções de construção, um retorno à noção de matéria, não como lugar ou superfície, mas como um processo de materialização que se estabiliza através do tempo para produzir o efeito de fronteira, de permanência e de superfície que chamamos matéria. (p. 26)

A noção de materialização tal como trabalhada por Butler (2002) está intimamente atrelada à noção foucaultina de poder como instância produtiva. Desse modo, as matérias quando constituídas produzem, performam e se abrem para novas rematerializações nas quais convergem poder e discurso. Logo, materializar e significar são atividades indissociáveis e sempre dizem de relações de poder que as tornam possíveis.

Como as estratégias nunca estão isoladas, incorporam máquinas, objetos, materiais, técnicas que se relacionam entre si. As materialidades não existem como entidades isoladas, mas em relação com outras entidades. Não apenas entram em relação com entidades que compartilham uma rede com elas, mas também passam a integrar novas redes (Moreira, 2000). Em cada uma dessas redes, novos aspectos de sua identidade se tornam importantes de modo que, em alguns casos, chega-se mesmo a questionar se se trata do mesmo objeto ou artefato. Esse é o caso dos anúncios que, integrando discursivamente imagens e texto, tornam públicos e, concomitantemente, legitimam estilos de vida que são atravessados por riscos em suas diversas tradições: como perigos, como probabilidade de ocorrência ou, ainda, como aventuras que podem trazer à tona emoções intensas.

\section{Sobre anúncios que usam glossários do risco}

Os discursos sobre risco definem territórios lingüísticos que demarcam campos de gestão. Nesses campos desenvolvemse maneiras específicas de falar sobre riscos. Assim, ao nos referirmos à linguagem dos riscos, embora usando o singular, não estamos propondo a existência de uma linguagem unitária (Spink \& Menegon, 2004). Estamos sugerindo que, no interior de cada campo, desenham-se formas de falar sobre riscos que lhe são específicas e que estão presas a três tradições de discursos sobre riscos por nós identificadas em estudos anteriores: a fala de senso-comum sobre perigos; a perspectiva do controle e disciplina e a perspectiva da aventura.

A primeira tradição, que antecede a emergência da palavra e, portanto, do conceito de risco (Spink, 2000), concerne às experiências de infortúnios muitas vezes imprevisíveis que fogem das possibilidades de cálculo. É uma tradição raramente considerada nas análises de risco, mas que certamente se faz presente nas análises discursivas dos modos de falar sobre risco no cotidiano.

A segunda tradição remete à perspectiva histórica dos discursos sobre risco colados à governamentalidade (Foucault, 1995), ou seja, ao governo de populações e ao risco objetivado pela quantificação. Está relacionada à crescente necessidade de governar populações, a partir da modernidade clássica. Referenda, portanto, medidas coletivas, destinadas a gerenciar relações espaciais - distribuição e o movimento de pessoas nos espaços físicos e sociais. Mas referenda, também, como sub-produto, os processos de disciplinarização da vida privada das pessoas. Esses processos se constituíram historicamente em duas etapas. A primeira está vinculada ao movimento higienista do final do século XIX e à moral da prevenção: higiene pessoal, higiene 
do lar e higiene moral. No decorrer do século XX, com o aumento da expectativa de vida resultante do controle de doenças infecciosas e da melhoria das condições sociais, as doenças crônicas tornaram-se preocupações centrais da saúde pública. Progressivamente, os conhecimentos médicos passaram a definir novos padrões de controle. Nessa segunda etapa dos processos de disciplinarização, cada pessoa, mediante acesso à informação, passa a ser responsável pelo auto-gerenciamento de sua saúde. O estilo de vida como forma de autocontrole é a face mais famosa dessa reorganização (Spink, 2000).

A terceira tradição, que aproxima os campos da Economia e dos Esportes, herda a positividade da aventura, apresentando especificidades discursivas quanto à lógica da governamentalidade. Assim, agrega um conjunto de repertórios sobre risco que exibe conotações que fazem do correr riscos uma prática necessária para alcançar determinados ganhos. Nessa perspectiva, é totalmente irrelevante se um dano é significado como prazeroso ou catastrófico: a relevância está na satisfação subjetiva - até mesmo na modalidade das emoções radicais - perante potenciais conseqüências e não numa lista predefinida de efeitos indesejáveis. As peculiaridades discursivas da tradição da aventura (considerando aqui o mundo dos negócios e dos esportes) mostram ser necessário reconhecer que as teorizações sobre risco precisam incorporar o sentido do risco desejado (Machlis \& Rosa, 1990).

Cada um desses territórios lingüísticos desenvolve vocabulários específicos que constituem glossários (ou repertórios lingüísticos) ativados em nossos enunciados sobre risco, conforme apresentado na Tabela 1.

Tal classificação decorre de pesquisas realizadas em diferentes momentos da pesquisa sobre as práticas discursivas sobre risco que incluíram: (a) a revisão da literatura sobre o tema e a exploração dos dicionários de etimologia de várias línguas indo-européias (Spink, 2001) e (b) a pesquisa diacrônica realizada na Folha de São Paulo (Spink et al, 2002). Com base na análise realizada na pesquisa com revistas aqui relatada, pudemos acrescentar novos verbetes - especialmente aqueles relacionados ao risco-aventura - criando, assim três dicionários específicos: risco-perigo (que inclui termos que antecedem a linguagem dos riscos propriamente dita, mas são por ela incorporados, sobretudo nas práticas discursivas do senso comum); risco-probabilidade (a linguagem dos riscos associada à probabilidade e cálculos de ocorrência) e o risco-aventura (as maneiras de falar sobre a positividade do risco).

Em certos contextos lingüísticos, esses glossários são disciplinarizados pelo gênero de fala aí predominante, como nas áreas tecnológica e na Epidemiologia onde risco é conceito, e não meramente um vocabulário usado para falar de certos fenômenos sociais. Mas na complexidade das interações cotidianas, os glossários se libertam de amarras estruturais, tornando-se repertórios disponíveis para dar sentidos às nossas experiências. Essa complexidade se faz presente, por exemplo, nas comunicações midiáticas de vários tipos, em que a diversidade de autores e temáticas abordadas transcende as demarcações territoriais dessas traduções discursivas. Daí o interesse nas revistas que circulam entre nós.

\section{Psicólogos sociais nas bancas de revista: apontamen- tos metodológicos}

Trabalhamos, nesta pesquisa com uma amostra de revistas. O primeiro passo na definição da amostra foi a sistematização das diversas características das revistas brasileiras em circulação na época em que iniciamos o trabalho de campo. Para isso, criamos um banco de dados tendo como fonte de informação o Anuário de Mídia - Revistas do ano de 2002. O banco de dados incluiu as seguintes informações sobre as 560 revistas presentes nesse Anuário: nome da revista; editora; data de início; temática; periodicidade; forma de circulação (porcentagem de venda em banca, distribuição por assinatura; distribuição gratuita); preço; circulação média, dados de registro e contato (ISSN; site; e-mail, etc.). Com base nesses dados definimos como critérios de inclusão na amostra a modalidade de distribuição, o endereçamento a públicos específicos e a periodicidade de circulação.

A distribuição de revistas no Brasil é feita de várias manei-

Tabela 1

Glossário do risco

\begin{tabular}{lll}
\hline \multicolumn{1}{c}{ Risco-perigo } & Risco-probabilidade & Risco-aventura \\
\hline Ameaça & Risco & Aventura \\
Perda & Aposta & Adrenalina \\
Sorte & Chance & Emoção \\
Perigo (perigoso) & Seguro (segurança) & Radical \\
Azar & Probabilidade & Extremo \\
Fortuna(do) & Prevenir (prevenção) & Desafio \\
Fatalidade & Arriscar (arriscado) & Ousadia \\
Obstáculo & & \\
Ventura & & \\
Destino & & \\
\hline
\end{tabular}


ras: venda direta em bancas, por assinatura, ou de forma dirigida quando se trata de publicações gratuitas e promocionais. Para garantir a disponibilidade das revistas ao público geral, definimos como critério de inclusão no corpus de análise a venda em bancas de jornal. Ficaram excluídas, portanto, as revistas que circulam apenas por assinatura ou que são distribuídas gratuitamente em circuitos restritos (como as revistas internas a empresas comerciais).

Para a classificação de temáticas adotamos as 49 caracterizações utilizadas pelo Anuário de Mídia - Revistas que, para fins de amostragem foram agrupadas em 15 categorias: (1) Informação semanal; (2) Interesse geral e atualidades; (3) Populações específicas (Femininas; Adolescentes; Infanto-juvenil; Masculinas); (4) Esporte, turismo e meio ambiente; (5) Economia e administração; (6) Assuntos domésticos; (7) Automobilismo e transportes; (8) Arte, cultura e música; (9) Engenharia, arquitetura e construção; (10) Alimentos, bebidas e gastronomia; (11) Eletrônica, ótica e mecânica; (12) Informática e telecomunicações; (13) Agropecuária e animais; (14) Saúde e beleza; (15) Outros.

As revistas que constam desse banco de dados circulavam em periodicidades diversas: semanais, quinzenais, mensais, bimensais, semestrais, anuais; sendo que as mais freqüentes eram as revistas mensais. Para fins de amostragem, essas diversas periodicidades foram agrupadas em três categorias: até um mês, mensais, e semestrais. Foram excluídas as revistas anuais $(\mathrm{n}=35)$ por serem guias e anuários de circulação bastante restrita e de difícil localização no mês escolhido para a compra das revistas.

A amostra, definida pela assessoria estatística da Pontifícia Universidade Católica de São Paulo, PUC-SP, levando em consideração as 15 (quinze) categorias e a periodicidade das revistas, incluiu 210 revistas: 24 até um mês, 134 mensais e 51 semestrais.

Na primeira semana de outubro, contatamos uma banca de jornal em frente à PUC-SP por ser bem suprida e pela disposição que o gerente mostrou em auxiliar em um trabalho que seria bastante difícil: o de localizar todas as revistas. A compra foi feita no mês de outubro por este não ser excessivamente marcado por determinados eventos do calendário cultural do país (por exemplo, dezembro, por causa do Natal; janeiro e fevereiro, pelas férias de verão e carnaval). Algumas revistas, apesar de incluídas na amostragem não puderam ser encontradas. Das 210 revistas foram localizadas e compradas 101 revistas. Pudemos notar que foi mais fácil comprar as revistas que circulam semanalmente e quinzenalmente, sendo que à medida que a circulação diminuía, a dificuldade de busca aumentava. Para tentar suprir essa falta, buscamos as revistas nas distribuidoras, mas a dificuldade permaneceu, principalmente com aquelas destinadas a públicos específicos.

Parte da dificuldade em encontrar essas revistas pode refletir a volatilidade desse mercado que introduz novas publicações com freqüência, muitas delas não conseguindo sobreviver em um mercado aparentemente competitivo.

Análise dos dados. O primeiro passo da análise foi a busca minuciosa de glossários do risco presentes nas matérias e anúncios de cada revista da amostra. Para isso, foi desenvolvida uma tabela contendo as seguintes informações: página, descrição sucinta dos conteúdos (título das matérias e nome do produto/ anunciante presente em cada página); presença de glossários do risco e imagens com risco-aventura. Esta tabela serviu de base para a seleção dos anúncios que constituíram o corpus da análise sobre glossários de risco em anúncios.

Para a análise do uso do glossário em anúncios, os produtos comercializados foram agrupados em 13 categorias: alimentícios; cigarros; seguros; automóveis e acessórios automobilísticos; serviços financeiros: eletrônicos e informática; moda, vestuário e acessórios; indústrias, empresas, laboratórios e marcas; produtos midiáticos e/ou culturais; produtos e atividades de lazer; saúde e equipamentos de segurança; e outros.

Em seguida, os produtos localizados foram distribuídos considerando as tradições discursivas, as palavras utilizadas no anúncio, a categoria de produtos, o produto propriamente dito, a temática da revista em que o anúncio foi localizado e a chamada principal do anúncio.

\section{Resultados}

\section{Usos do glossário do risco para vender produtos}

Encontramos um total de 67 produtos que utilizaram o glossário do risco em 11 das 13 categorias de produtos utilizadas na pesquisa. Ficaram excluídos apenas as categorias cigarros (anúncios proibidos a partir da Lei 10.167 de 27/12/2000) e produtos midiáticos e culturais.

Desta primeira aproximação, deduz-se que a linguagem dos riscos predomina na venda de produtos e atividades de lazer; encontramos 16 produtos dessa categoria. Mas há, também, algumas observações de cunho metodológico que precisam ser feitas neste momento. Primeiro, em oito anúncios, houve uso de mais de um repertório para vender um mesmo produto de modo que o total de vocábulos ou repertórios e de produtos não será o mesmo nas tabelas que detalham o uso dos glossários de diferentes tradições. Em segundo lugar, embora estivessem incluídas na amostra revistas destinadas a públicos variados, foi interessante observar que os anúncios de um mesmo produto não variaram em função da revista em que foram publicados: o endereçamento pode subsidiar a decisão de veiculação do anúncio de um certo produto, mas os custos envolvidos na produção do anúncio provavelmente levam a utilizar o mesmo anúncio, independentemente da temática da revista.

Esses 67 produtos foram anunciados utilizando 81 vocábulos ou repertórios das três tradições discursivas: risco-perigo $(\mathrm{n}=4)$; risco-probabilidade $(n=47)$ e risco-aventura $(n=30)$. A Figura 1 permite visualizar a relação entre essas tradições discursivas e as categorias de produtos anunciados.

\section{A predominância do risco-probabilidade}

Conforme pode ser visto na Tabela 2, o glossário do riscoprobabilidade está concentrado na venda de produtos relacionados à saúde e higiene (10/11), serviços financeiros (8/10), seguros (7/7), equipamentos de segurança (5/6) e indústria, empresas e marcas $(4 / 5)$.

Como exemplo do uso do glossário do risco-probabilidade em produtos relacionados à saúde e higiene, encontramos, na revista Caras (№ 521, 2003, p. 44), um anúncio do desodorante 
Tabela 2

Freqüência de produtos anunciados por categoria de produto e tradições de discurso sobre risco

\begin{tabular}{lrccc}
\hline \multicolumn{1}{c}{ Tipo de produto } & N & Risco-perigo & $\begin{array}{c}\text { Risco- } \\
\text { probabilidade }\end{array}$ & $\begin{array}{c}\text { Risco- } \\
\text { aventura }\end{array}$ \\
\hline Produtos e atividades de lazer & 16 & 1 & 3 & 15 \\
Saúde e higiene & 9 & 0 & 10 & 1 \\
Serviços financeiros & 7 & 2 & 8 & 1 \\
Moda, vestuário e acessórios & 6 & 0 & 3 & 3 \\
Indústrias, empresas, marcas e laboratórios & 6 & 0 & 4 & 1 \\
Veículos e acessórios & 6 & 0 & 3 & 5 \\
Seguros & 6 & 0 & 7 & 0 \\
Equipamentos de segurança & 5 & 1 & 5 & 0 \\
Produtos alimentícios & 2 & 0 & 1 & 1 \\
Eletrônicos e informática & 2 & 0 & 2 & 1 \\
Outros & 2 & 0 & 1 & 2 \\
\hline Total & 67 & 4 & 47 & 30 \\
\hline
\end{tabular}

Observação: mais de um glossário pode ser usado para anunciar um mesmo produto.

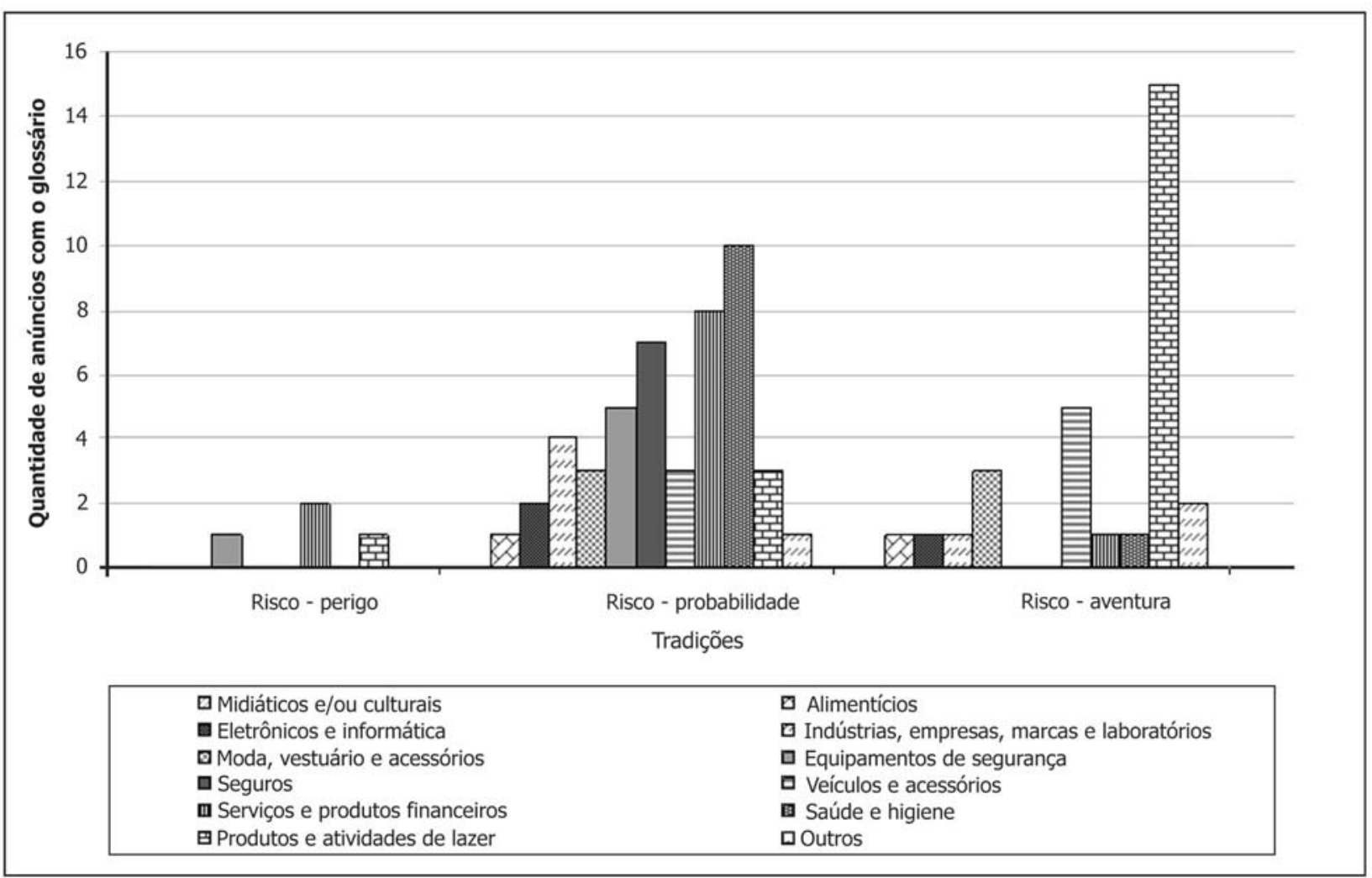

Figura 1. Glossários do risco por categoria de produto e tradições discursivas.

Dove Fresh com a seguinte legenda: "Quando o desodorante não protege você, não há produção que se sustente. Novo Dove Fresh. A proteção que você precisa". O cartão Unibanco, por sua vez, anunciava seu serviço financeiro - o cartão Unibanco - na revista Veja (№ 43, 2003, p. 2/3): "Você quer usar seu cartão com segurança. Por isso, o Unicard Unibanco inventou a uniproteção, a mais avançada tecnologia do mundo.” E, na categoria seguros, a General Seguros oferecia seus serviços na revista Náutica ( $N^{\mathrm{o}}$ 182, 2003, p. 151): “O seguro de quem conhece o mar. Um produto completo, desenvolvido para oferecer tranqüilidade e 
segurança às suas atividades de lazer náutico.”

Segurança e proteção, conforme discutido por diversos autores (Ayres, 1997; Bernstein, 1997; Douglas, 1992; Spink, 2001) são vocábulos associados à mentalidade securitária decorrente do amplo uso das estimativas de probabilidade na área da saúde (em decorrência dos avanços da Epidemiologia) e do desenvolvimento da indústria de seguros (Ewald, 1991).

\section{A tradição do risco-aventura: ênfase no lazer}

Já a tradição risco-aventura é usada para vender, sobretudo, produtos e atividades de lazer $(\mathrm{n}=15 / 19)$ e veículos e acessórios $(\mathrm{n}=5 / 8)$, aparecendo também, com menor incidência, na venda de moda, vestuário e acessórios $(\mathrm{n}=3 / 6)$. A tradição de risco-aventura não é utilizada para vender produtos relacionados à segurança.

São exemplos do uso do glossário do risco-aventura para a venda de produtos e atividades de lazer os seguintes anúncios: (1) Motor Honda em Jet-sky na revista Náutica, № 182,2003 , p.16: Yamaha, 2003. "Adrenalina à flor da pele"; (2) Smolder, marca de produtos associados ao surf, veiculado na revista Fluir, $\mathrm{N}^{\mathrm{o}}$ 216, 2003, p. 125: "O tampo para dentro de um tubo. O corpo ferve, a vida passa decidida no mar. For extreme adventures"; e (3) Adventure Sports Fair, nas revistas Isto É (No 1778, 2003, p. 85); Aventura e Ação (№ 111, 2003, p. 2/3) e Playboy (№ 339, 2003, encarte, p. 5): “O mundo da aventura se encontra aqui".

Quanto à venda de produtos relacionados com veículos e acessórios, a Fiat anunciava seu Strada Adventure na Top Magazine ( $\mathrm{N}^{\mathrm{O}}$ 57, 2003, p. 19) com os seguintes dizeres: "Suspensão e pneus preparados para a aventura". Até mesmo as empilhadeiras Lide, em anúncio veiculado na Isto É, Dinheiro ( $\mathrm{N}^{\mathrm{o}}$ 322, 2003, p. 3) enfatizavam a ousadia e a flexibilidade, valores empresariais reconhecidos como centrais no capitalismo neo-liberal: "Para enxergar mais longe sua empresa precisa ser ousada e flexível".

\section{Uso do glossário do risco-perigo: uma questão em aberto}

A tradição do risco-perigo foi pouco utilizada para vender produtos: dos sessenta e sete anúncios localizados na amostra, esse glossário foi usado apenas quatro vezes.

Dada a baixa freqüência de uso desse glossário, consideramos importante a análise das situações de uso, de modo a responder às perguntas: usam-se termos do glossário agregados aos sentidos atribuídos à tradição do risco-perigo? Ou os mesmos termos migraram, sobrevivendo ao tempo e ganharam novos sentidos?

Dois anúncios utilizaram o termo sorte e ambos referiam-se a serviços financeiros. O primeiro, um anúncio da Caixa veiculado na revista Caras (№ 521, 2003, p. 185), afirmava "Todo dia pode ser seu dia de sorte". Integrava, assim, a falta de controle associada à sorte e destino com o linguajar altamente probabilístico dos produtos financeiros. O mesmo artifício discursivo foi usado pela mesma empresa para anunciar seu cartão de crédito na Veja (No 43, 2003, p. 60): “Agora todo o dia pode ser seu dia de sorte. Basta ter um cartão de crédito da Caixa e fazer no mínimo 50 compras no cartão."

O terceiro anúncio, do jogo Game Boy na revista Nintendo
World (Outubro, 2003, p. 39), trazia o termo obstáculo: “Ajuste seu carro para superar obstáculos". E o quarto, de kits sinalizadores (Náutica, № 182, 2003, p.104) alertava: "Mais eficiência em situação de perigo".

Certamente a Economia está intimamente associada ao enquadre dos jogos. Estes, de um lado, foram o cenário propício para o desenvolvimento da teoria da probabilidade, tão central na conceituação do risco (Bernstein, 1997). Mas há uma longa história dos "jogos de azar" na qual sorte e destino se fizeram presentes. E, por mais que as aventuras no mar contem hoje com sofisticados recursos técnicos, a previsão do tempo continua a ser um desafio para a meteorologia e os aventureiros.

\section{Riscos vendem? Vendem-se riscos?}

Voltando à pergunta que orientou esta análise - se riscos vendem produtos - a resposta certamente é afirmativa, todavia, devemos salientar que se trata mais do controle de riscos potenciais do que da apologia do risco. Ou seja, mesmo quando aparentemente "vendem-se riscos", como no caso do de produtos relacionados ao risco como aventura, vendem-se, de fato, emoções associadas à experiência do risco, mas com o cinto de segurança da qualidade dos produtos anunciados sustentados por estratégias de segurança, que incluem treinamento, equipamentos especializados, monitoria e seguros.

No que se refere às tradições discursivas sobre risco, que são atualizadas na venda de produtos, obviamente cada produto (ou serviço) está inserido numa rede que inclui suas características como artefato técnico, seu uso tradicional ou potencial, seu poder discursivo de sedução do consumidor e outras tantas características que o materializam, como propõe Butler (2002), com efeitos de fronteira, permanência e superfície daquilo que chamamos matéria. Entretanto, nenhum produto se materializa por si só. Materializações implicam agenciamentos de vários tipos: pessoas que compram produtos e os usam de formas mais ou menos convencionais. Tomando como exemplo o Fiat Strada Adventure, posso vendê-lo usando o glossário do risco-aventura focalizando uma única característica do produto: "Suspensão e pneus preparados para aventura". Que efeitos têm essa forma de usar a linguagem dos riscos?

A venda da ilusão da aventura por meio da segurança oferecida por pneus e suspensão adequadas. Imaginem a complexidade da equipe da Fiat envolvida nessa empreitada: desenhistas, engenheiros, marqueteiros e administradores que têm de conciliar interesses de empresas diversas (produtoras de pneus e de carrocerias). Em suma, as tradições discursivas não têm autonomia, mesclam-se para vender produtos que, como materializações, se inserem em redes complexas que incluem humanos e não-humanos, práticas discursivas e matérias.

Vale lembrar que, nesta fase da análise sobre risco-aventura na mídia, nosso foco estava centrado apenas nas palavras usadas para vender produtos. Palavras e imagens, como teremos oportunidade de ver em outros relatos da análise dos dados desta pesquisa, colaboram para produzir mensagens mais potentes sobre produtos em busca de consumidores. Mensagens possíveis, porque leitores-consumidores estão familiarizados com usos da linguagem dos riscos em práticas sociais diversas, conforme 
tivemos oportunidade de discutir em estudos anteriores do Grupo de Pesquisa (por exemplo, Cardona, 2004; Menegon, 2006).

Quais produtos são vendidos por meio das práticas discursivas sobre risco? Hipoteticamente, qualquer produto. Todo e qualquer produto, seja um artefato ou serviço, traz consigo aspectos relacionados à linguagem dos riscos. Produtos alimentícios ou de beleza são testados segundo rígidos códigos bioéticos e as mensagens ao público, por sua vez, são acompanhadas e zeladas em seus aspectos éticos por órgãos governamentais e para-governamentais (como o CONAR, no caso da propaganda). Vendem-se produtos não pelo risco, mas justamente pela segurança que oferecem perante riscos variados.

Todavia, certamente há produtos que são vendidos porque carregam, em si, mensagens relacionadas à experiência positivada de risco: pacotes turísticos que incluem esportes de aventura; produtos direcionados aos consumidores de atividades de riscoaventura; bebidas, que cautelosamente vendem emoções (mas advertem que "se beber, não dirija"). O caso dos anúncios de cigarro, que não integram o corpus de análise porque proibidos desde dezembro de 2000, constituem um bom exemplo. Algumas marcas, como Hollywood e Marlboro, desde muito cedo aliaram seu apelo e sedução às atividades na natureza. Curiosamente, à medida que a venda e marquetização desses produtos passava a ter um maior controle governamental, exacerbava-se o sentido de aventura associado ao fumo. O risco à saúde, quiçá, passou a ser ressignificado como a paixão pelo risco (a Fórmula 1, os esportes radicais, os adventure teams).

Por fim, para quem são vendidos os produtos cujos anúncios fazem uso do glossário do risco? Retornemos às posições tomadas anteriormente: as revistas têm por principal característica serem endereçadas a segmentos específicos da população. Por sua vez, anunciantes buscam revistas com ampla circulação entre populações que têm acesso a bens. Forma-se, assim, um círculo, ou um encadeamento de interanimações dialógicas que incluem: editores e seus projetos editoriais, público segmentado que compra esse projeto editorial, anunciantes que vêm nesse mesmo público um potencial de mercado. Ou seja, revistas, produtos e leitores formam um todo indiferenciado: para entender uma parte, todas as partes têm que ser consideradas. Como sugere Butler (2002), quiçá o que temos são movimentos de materialização que se estabilizam através do tempo e que necessitam do tempo para exercer o papel de uma fronteira, adquirir densidade suficiente para que neles se inscrevam sentidos e relações de poder.

\section{Agradecimentos}

As autoras agradecem ao $\mathrm{CNPq}$, pela bolsa de produtividade em pesquisa da primeira autora, e à professora Yara Castro, pela colaboração na definição da amostra.

\section{Referências}

Anuário de mídia - revistas (2002). São Paulo: Editora Meio e Mensagem. Ayres, J. R. de C. M. (1997). Sobre o risco. São Paulo: Hucitec.

Bakhtin, M. (1994). The problem of speech genres. In C. Emerson \& M. Holquist (Orgs.), Speech genres and other late essays (pp. 60-102) Austin, Texas: University of Texas Press.

Beck, U. (1993). Risk society: towards a new modernity. Londres: Sage.

Bernstein, P. L. (1997). Desafio aos deuses: a fascinante história do risco. Rio de Janeiro: Campus.

Butler, J. (2002). Cuerpos que importan: sobre los limites materiales y discursivos del "sexo". Buenos Aires: Paidós.

Cardona, M. C. G. (2004). Linguagem dos riscos e sujeitos posicionados: o uso de agrotóxicos no Vale de Quíbor, Venezuela. Tese de Doutorado não-publicada, Pontifícia Universidade Católica de São Paulo, São Paulo.

Cortese, A. J. (1999). Provocateur: images of women and minorities in advertising. Oxford, Reino Unido: Rowman \& Littlefield.

Douglas, M. (1992). Risk and blame. Londres/Nova York: Routledge.

Ewald, F. (1991). Insurance and risk. In G. Burchell, C. Gordon, \& P. Miller (Orgs.), The Foucault effect: studies in governmentality (pp. 197-210). Chicago: The University of Chicago Press.

Foucault, M. A (1995). Microfisica do poder. Rio de Janeiro: Graal.

Giddens, A. (1991). Modernity and self-identity. Cambridge, Reino Unido: Polity.

Giddens, A. (1998). Risk society: the context of British politics. In J. Franklin (Org.), The politics of risk society. Cambridge, Reino Unido: Polity.

Machlis, G. E., \& Rosa, E. A. (1990). Desired risk: broadening the social amplification risk framework. Risk Analysis, 10, 161-168.

Menegon, V. S. M. (2006). Entre a linguagem dos direitos e a linguagem dos riscos: os consentimentos informados na reprodução humana assistida. São Paulo: FAPESP / EDUC.

Moreira, T. (2000). Difference and ontological fluidity: cerebral angiography and neurosurgical practice. Social Studies of Science, 30, 421-446.

Scalzo, M. (2004). Jornalismo de revista. São Paulo: Contexto.

Schneider, A. (2005). Conar 25 anos: ética na prática. São Paulo: Terceiro Nome.

Spink, M. J. (2000). Contornos do risco na modernidade reflexiva: contribuições da psicologia social. Psicologia \& Sociedade, 12, 156-173.

Spink, M. J. (2001). Trópicos do discurso sobre o risco: risco-aventura como metáfora na modernidade tardia. Cadernos de Saúde Pública, 17, 1277-1311.

Spink, M. J., Aragaki, S., \& Alves, M. P. (2005). Da exacerbação dos sentidos no encontro com a natureza: contrastando esportes radicais e turismo de aventura. Psicologia: Reflexão e Crítica, 18, 26-38.

Spink, M. J., Galindo, D., Cañas, A., \& Souza, D. (2004) Onde está o risco? Os seguros no contexto do turismo de aventura. Psicologia e Sociedade, 16, 81-89.

Spink, M. J., Medrado, B., \& Mello, R. P. (2002). Perigo, probabilidade e oportunidade: a linguagem dos riscos na mídia. Psicologia, Reflexão e Crítica, 15(1), 151-164.

Spink, M. J., \& Menegon, V. M. (2004). Práticas discursivas como estratégias de governamentalidade: a linguagem dos riscos em documentos de domínio público. In L. Iñiguez (Org.), Manual de análise do discurso em ciências sociais (pp. 258-311). Petrópolis: Vozes. 
Mary Jane P. Spink, doutora em Psicologia Social pela University of London (Reino Unido), é professora titular na Pontifícia Universidade Católica de São Paulo. Endereço para correspondência: Programa de Estudos Pós-graduados em Psicologia Social; Pontifícia Universidade Católica de São Paulo; Rua Monte Alegre 984 (Perdizes); CEP 05014-901; São Paulo, SP. Telefone/Fax (11) 3670-8520. E-mail: mjspink@pucsp.br

Dolores Galindo, mestre em Psicologia Social, é doutoranda do Programa de Estudos Pós-graduados em Psicologia Social da Pontifícia Universidade Católica de São Paulo.

Raquel Noel Ribeiro, graduada em Psicologia, é mestranda do Programa de Estudos Pós-graduados em Psicologia Social da Pontifícia Universidade Católica de São Paulo.

Maria Annita Ornellas, graduada em Psicologia, é membro do Núcleo de Estudos e Pesquisas em Práticas Discursivas e Produção de Sentidos, Programa de Estudos Pós-Graduados em Psicologia Social da Pontifícia Universidade Católica de São Paulo. 